\title{
A NEED FOR EYE LENS DOSIMETRY IN NUCLEAR MEDICINE
}

\author{
M. Wrzesień1 ${ }^{*}$, L. Królicki² , Ł. Albiniak', J. Olszewski \\ ${ }^{1}$ University of Lodz, Faculty of Physics and Applied Informatics, Department of Nuclear Physics and Radiation Safety, \\ Lodz, Poland \\ ${ }^{2}$ Medical University Warsaw, Nuclear Medicine Department, Warsaw, Poland \\ 3 Nofer Institute of Occupational Medicine, Department of Radiation Protection, Lodz, Poland
}

\begin{abstract}
Background: Changing the individual dose limit for the lens of the eye from a value of $150 \mathrm{mSv}$ per year to a level of $20 \mathrm{mSv}$ (averaged over defined periods of five years or $50 \mathrm{mSv}$ in a single year) means that issues related to routine eye lens dosimetry become interesting from the point of view of radiation protection. This could mean that the dosimeter designed to measure the doses at the level of the eye lens may become the next dosimeter routinely worn by nuclear medicine workers occupationally exposed to ionising radiation. The dosimeters currently used in nuclear medicine are the personal dosimeter and the ring dosimeter. Will this also be the case for nuclear medicine employees? In this interdisciplinary branch of medicine, the factors that cause the highest risk of radiation exposure of personnel are the process of manual handling, i.e. the process of preparing a radiopharmaceutical called labelling. Most of the radiopharmaceuticals used in nuclear medicine are labelled manually. In Poland, the exception from this rule is when radiopharmaceuticals are produced for the needs of positron emission tomography (PET), which are labelled using automatic processes. Manual procedures also include the process of radiopharmaceutical injection to the patients. The aim of the work was to assess the exposure of eye lenses of workers in nuclear medicine, as well as of the personnel in centers that produce radiopharmaceuticals for PET diagnostics, from the viewpoint of advisability of routine eye lens exposure monitoring, taking into account changes in the dose limit for the lens of the eye. Methods: The results of own measurements of the personal dose equivalent $H p(3)$, carried out in five nuclear medicine departments in Poland, as well as in two centers producing radiopharmaceuticals for PET, were subject to analysis. The analysis includes two most frequently used radionuclides for diagnostic purposes, namely ${ }^{99 m} \mathrm{Tc}$, ${ }^{18} \mathrm{~F}$ and the less frequently used ${ }^{68} \mathrm{Ga}$, in addition to ${ }^{131} \mathrm{I}$, which is used for therapeutic purposes. Dosimetric measurements were made using thermoluminescent detectors of domestic manufacture. Results \& Conclusions: Estimated analysis of the annual exposure makes it possible to indicate cases where the maximum annual value of personal dose equivalent, in terms of $\mathrm{Hp}(3)$, exceeds threefold the new limit value specified at $20 \mathrm{mSv} /$ year.
\end{abstract}

Keywords: Dose limit, dosimetry, eye lens, $H p(3)$, nuclear medicine, radionuclide, radiopharmaceutical

\section{INTRODUCTION}

The discussion about the exposure received by eye lenses of workers occupationally exposed to ionising radiation has been going on for some time already. Its origin is largely associated with radiobiological aspects and thus with the deterministic effects that ionising radiation is able to induce at the cellular level in the lens of the eye. We are talking here about the cataract. In the present International Commission on Radiological Protection (ICRP) approach, cataract induction is a deterministic effect with a definite threshold. This threshold is between 2 and 10 Gy for acute exposure, and 8 Gy for prolonged exposure [1]. Interventional radiology is the reason for interest in the exposure of the eye lenses of workers occupationally exposed to ionizing radiation. This interest, however if only due to the dose reduction for the eye lens recommended by ICRP [1] - propagates to other medical branches where ionizing radiation is used, and in particular to nuclear medicine. What makes nuclear medicine special is the form of the radiation source. It uses the so-called open radiation sources in the form of radiopharmaceuticals, which are a combination of a radioactive isotope with a non-radioactive chemical compound. This specific chemical hybrid often requires a complicated process of radionuclide production; the procedure of labeling a chemical compound with a manufactured radionuclide itself requires many complex, often manual, activities. Since most procedures in the field of nuclear medicine are performed manually, the exposure of personnel who perform the procedures using radiopharmaceuticals becomes interesting not just from the point of view of exposure of hands or the whole body, but of eye lenses as well. It should be remembered that the personnel employed in nuclear medicine are covered by individual dosimetry, where the dose is measured on the skin of the hands using a ring dosimeter. The second dosimeter makes it possible to assess the effective dose. However, would the reduction of the

* malgorzata.wrzesien@uni.lodz.pl 
dose limit to the eye lens from $150 \mathrm{mSv} / \mathrm{year}$ [2] to 20 $\mathrm{mSv}$ per year $[1,3-5]$ mean the necessity of routine application of another dosimeter measuring doses to the eye lens? An attempt to answer this question requires consideration of several issues, including shields against ionizing radiation used in nuclear medicine facilities and centres producing radiopharmaceuticals (CPR) for positron emission tomography (PET). In some nuclear medicine facilities, workstations designed for work with radionuclides are made of lead bricks supplemented in the upper part with a lead glass window. Radiological protection provided by such shields reduces the dose rate of ionizing radiation to the body or to the head (sheltered body parts) by a factor up to $10^{8}$ [6]. Often, special fullprotective laminar chambers are also used, adapted to work with radioactive isotopes. In the case of shortlived radionuclides dedicated to the PET technique, their production was largely automated. Another element that may affect the level of personnel exposure is the type of radioactive source used - the radionuclide. In nuclear medicine, a wide range of radioactive nuclides is used, of which ${ }^{99 \mathrm{~m} T c},{ }^{18} \mathrm{~F}$ are the most commonly used ones in Poland [7]. In the case of therapy, ${ }^{131} \mathrm{I}$ is used [8]. Within this context, the ${ }^{68} \mathrm{Ga}$ radionuclide is interesting, which is among less frequently used radionuclides, but the degree of complexity in obtaining a radiopharmaceutical labeled with this radionuclide may be of some significance in the assessment of staff exposure. And so the complexity of procedures and manual performance of activities aimed at obtaining radiopharmaceuticals can be reflected in the values recorded by the dosimeter. In this respect, among the above-mentioned radionuclides, the most complicated fully manual process of obtaining the labels themselves concerns generator-originated radionuclides $-{ }^{68} \mathrm{Ga}$ and ${ }^{99 \mathrm{~m} T c}$. In the case of ${ }^{18} \mathrm{~F}$, the production of the label is automated, however manual processes include quality control of labeled fluorodeoxyglucose ( $\left.{ }^{18} \mathrm{~F}-\mathrm{FDG}\right)$.

The aim of the work was to assess the exposure of eye lenses of workers in nuclear medicine, as well as of the personnel in centers that produce radiopharmaceuticals for PET diagnostics, from the point of view of advisability of routine eye lens exposure monitoring, taking into account the changes in the dose limit for the lens of the eye.

\section{MATERIALS AND METHODS}

In order to measure the doses, high-sensitivity thermoluminescent detectors (TLD), made of lithium fluoride produced in Poland (LiF: $\mathrm{Mg}, \mathrm{Cu}, \mathrm{P}-\mathrm{MCP}-\mathrm{N}$ ), were used. The detectors were calibrated in the Second Standards Laboratory in the Nofer Institute of Occupational Medicine in Łódź. For this purpose, a source of gamma radiation was used - ${ }^{137 \mathrm{Cs}}$ $\left({ }^{6} \mathrm{Co} /{ }^{137} \mathrm{Cs}\right.$ irradiator). During the calibration process, we also used $X$ radiation generated at $150 \mathrm{kV}$ voltage and additional filtration of $2.5 \mathrm{~mm}$ tin. The detectors have been calibrated in accordance with ISO 4037-1 [9] and ISO 4037-3 [10] in kerma units in the air from $0.05 \mathrm{mGy}$ to $30 \mathrm{mGy}$. Corrections resulting from the differences between the energy of radiation emitted during the calibration exposure and the gamma radiation energy emitted by individual isotopes were taken into account. The conversion factor $H \mathrm{p}(3)$ was obtained by approximating the $H \mathrm{p}\left(3,0^{\circ}\right) / K$ coefficients obtained in the photon energy range from $0.01 \mathrm{MeV}$ to $10 \mathrm{MeV}$, determined by Vanhavere et al $[11,12]$. A 20 $\mathrm{cm}$ cylinder was also used. The thermoluminescent detectors were read using a RA'04 reader (Poland) and Fimel (France). The detectors were subjected to a typical annealing process in a PTW-Freiburg oven so that they could be reused in subsequent measurements. During the measurements, the detectors were placed within hoops worn by the staff at the height of the eyebrows in such a way that the TL detector was located directly above the appropriate lens of the eye.

Statistical analysis to compare the left and right eye dosimeters on each person was performed with the Mann-Whitney test using STATISTICA v. 10.o.MR1. Any differences found were considered statistically significant if the p-value was below 0.05 .

\section{RESULTS AND DISCUSSION}

Figure 1 presents the $H p(3) / A$ values recorded during procedures performed by personnel using the four different radionuclides.

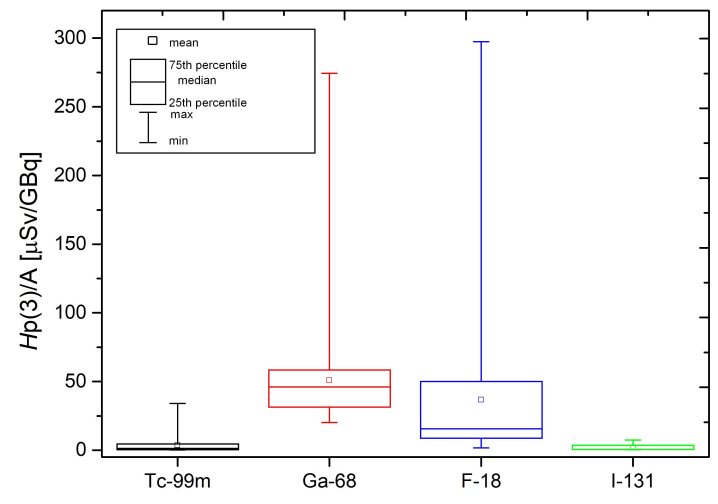

Figure 1. $H \mathrm{p}(3) / \mathrm{A}$ values recorded during procedures performed with the following radionuclides: ${ }^{99 \mathrm{~m} T c},{ }^{68} \mathrm{Ga},{ }^{18} \mathrm{~F}$, and ${ }^{131} \mathrm{I}$.

Figure 1 shows the range of possible $H p(3) /$ A values recorded by the detectors responsible for measuring the personal eye dose equivalent. The data are particularly interesting for two radionuclides $-{ }^{68} \mathrm{Ga}$ and ${ }^{18} \mathrm{~F}$. Both radionuclides are used for diagnostic purposes, but their production method is different. The ${ }^{68} \mathrm{Ga}$ is a radionuclide from a ${ }^{68} \mathrm{Ge} /{ }^{68} \mathrm{Ga}$ generator while ${ }^{18} \mathrm{~F}$ is a typical representative of the short-lived radionuclides produced using a cyclotron device. Despite the automated production process of the ${ }^{18} \mathrm{~F}$ marker, the manually performed quality control procedures of the fluorodeoxyglucose $\left({ }^{18} \mathrm{~F}-\mathrm{FDG}\right)$ and the ${ }^{18} \mathrm{~F}-\mathrm{FDG}$ injection process caused the maximum $H \mathrm{p}(3) / \mathrm{A}$ values recorded by $\mathrm{TL}$ detectors to be potentially close to $300 \mathrm{mSv} / \mathrm{GBq}$. Not much less - 
about $280 \mathrm{mSv} / \mathrm{GBq}-\mathrm{TL}$ detectors registered in the case of procedures performed with ${ }^{68} \mathrm{Ga}$ radionuclide. Less complicated manual procedures carried out by the personnel with the $99 \mathrm{~m} \mathrm{Tc}$ radionuclide $-\mathrm{a}$ representative of a group of radionuclides from the short-lived radionuclides generator $\left({ }^{99} \mathrm{Mo} / 99 \mathrm{mTc}\right)-$ resulted in a maximum $H \mathrm{p}(3) / \mathrm{A}$ value of $34 \mathrm{mSv} / \mathrm{GBq}$. In practice, procedures with the use of ${ }^{131}$ I radionuclide in the form of sodium iodide focus on the ${ }^{131} \mathrm{I}$ unpacking process and measuring the activity of the capsule containing said ${ }^{13}$ I , hence the last item in the category of TLD-registered values with a maximum $\mathrm{Hp}(3) /$ A value of just over $7 \mathrm{mSv} / \mathrm{GBq}$.

In Poland, a dosimeter measuring the personal eye dose equivalent $\mathrm{Hp}(3)$ has been commercially available for some time. However, it allows dose-measuring only in one position. Therefore, if this dosimeter is to be used in the routine measurement of the dose on the eye lens, will the exposure characteristics of the left and right eye lens of employees in nuclear medicine facilities and radiopharmaceutical production centers be the same or similar? Figure 2 shows the mean $H \mathrm{p}(3) / \mathrm{A}$ (with standard deviation) values recorded by TL detectors placed above the left and right lens of the eye during procedures using the four different radionuclides.

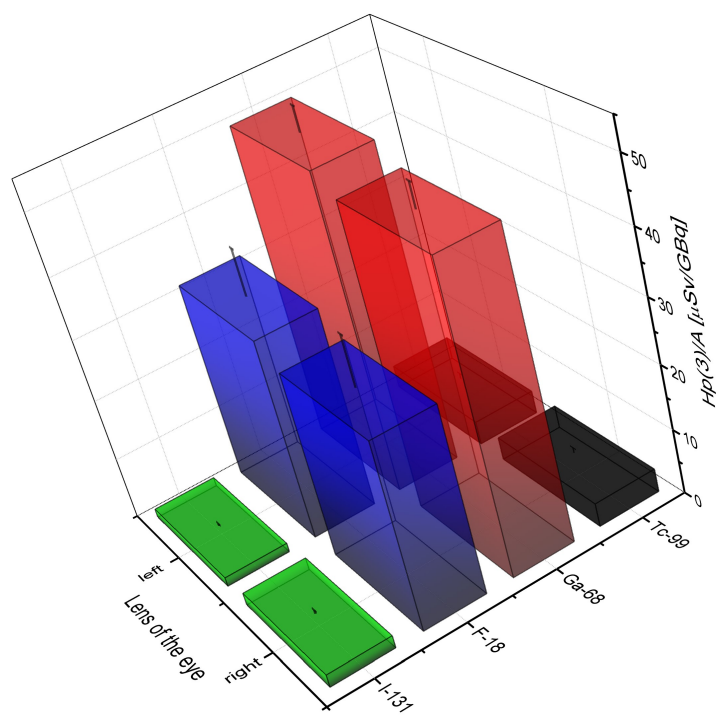

Figure 2. Mean $H \mathrm{p}(3) / \mathrm{A}$ values with standard deviation recorded by thermoluminescent detectors placed over the left and right lens of the eye during the procedures using radionuclides: ${ }^{99 \mathrm{~m} T c},{ }^{88} \mathrm{Ga},{ }^{18} \mathrm{~F},{ }^{131} \mathrm{I}$.

Figure 2 shows that even if differences between the $H \mathrm{p}(3) /$ A values for the left and right eye lens exist, they become apparent only during a detailed statistical analysis involving a comparison of $H \mathrm{p}(3)$ dose distributions, taking into account the employment structure in a given nuclear medicine facilities and procedures performed [13-15].

Another factor that can affect the level of exposure of the eye lens of personnel of nuclear medicine facilities and centers of production radiopharmaceuticals based on short-lived isotopes is the complexity of procedures performed and the fact that the vast majority of activities that result preparing of radiopharmaceuticals are done manually. Figure 3 presents the percentage of activities performed by staff in the total value of $H \mathrm{p}(3)$ obtained during the preparation and injection of radiopharmaceuticals based on four radionuclides.

When analyzing the impact of procedures performed by the staff, it should be remembered that each radiopharmaceutical being prepared sometimes requires extremely different procedures, including the production of the radionuclide marker. Whenever the time of contact with the radioisotope is short which may be associated with a small interference of the employee in some of the production processes or preparation of the radiopharmaceutical, which occurs, e.g. during the ${ }^{99} \mathrm{Mo} / 99 \mathrm{mTc}$ generator elution process or unpacking ready-to-administer capsules of sodium iodide, the percentage of these activities in the total dose reaches a maximum of a few percents.

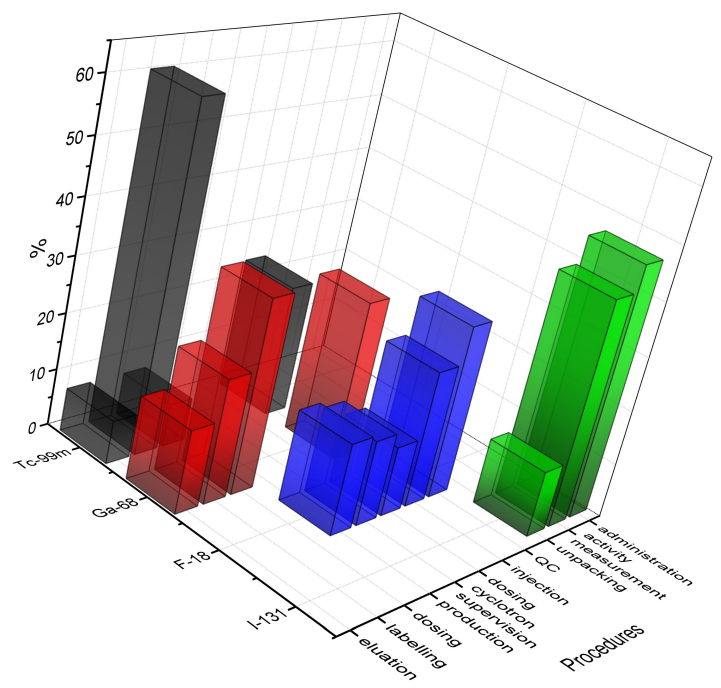

Figure 3. Percentage of activities performed by the personnel in the total dose of $\mathrm{Hp}(3)$ received during the preparation and injection of radiopharmaceuticals based on ${ }^{99 \mathrm{mTc}},{ }^{68} \mathrm{Ga},{ }^{18} \mathrm{~F}$, ${ }^{131}$ I radionuclides.

Wherever a sufficiently long time is required that the employee must devote to the proper preparation of radiopharmaceuticals, such as: the labelling process of radiopharmaceutical with $99 \mathrm{~m} \mathrm{Tc}$, dispensing the doses of ${ }^{68} \mathrm{Ga}$-DOTA-TATE for patients or ${ }^{18} \mathrm{~F}$-FDG quality control procedure; the percentage of these activities in the total dose is within the range of less than $40 \%$ to close to $55 \%$.

The provision of EU Directive 2013/59/EURATOM [16] obliged Poland, by February 6, 2018, to amend the national law regarding the limit value of ionizing radiation doses, so that the value of the limits corresponds to those contained in the directive (in particular, it concerns eye lenses). Unfortunately, at the time of preparing this work, this change has not yet been legally implemented. Nevertheless, a 7.5-fold 
limitation of the dose limit value, which sooner or later must be reflected in legal provisions, may mean for employees, regardless of the specifics associated with the form or type of source emitting ionizing radiation, the need to monitor the value of doses for eye lenses. It is, therefore, important from this point of view to estimate the annual exposure of the eye lens of employees occupationally exposed to ionizing radiation in nuclear medicine centers using ${ }^{99 \mathrm{~m}} \mathrm{Tc},{ }^{18} \mathrm{~F},{ }^{68} \mathrm{Ga}$ and ${ }^{131}$ I radionuclides.

The annual $\mathrm{Hp}(3)$ was estimated assuming the worst-case scenario: 260 days of work during the year and that all procedures involving the radionuclide are performed by one employee $[14,15]$. Figure 4 presents the maximum estimated annual $\mathrm{Hp}$ (3) of personnel of nuclear medicine departments and facilities producing radiopharmaceuticals for use in PET, taking into account the current dose limit for the lens of the eye of $150 \mathrm{mSv}$ per year and the new one at $20 \mathrm{mSv} /$ year.

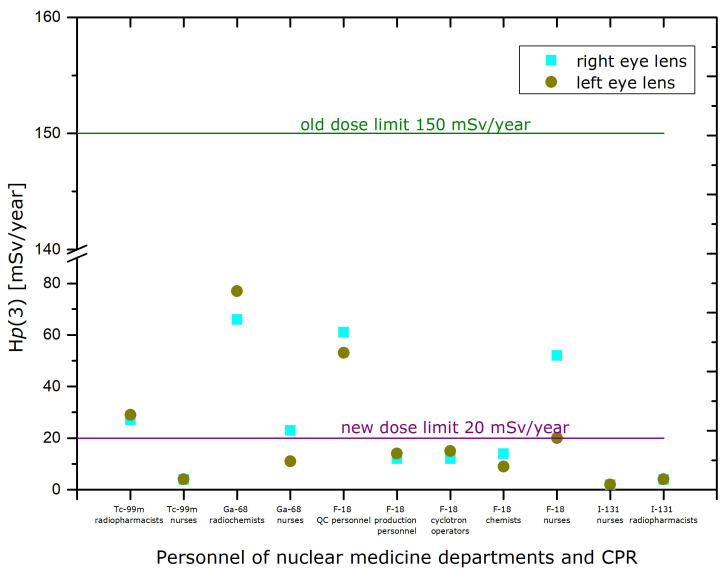

Figure 4. Annual $\mathrm{Hp}$ (3) estimates for the personnel of nuclear medicine departments and the personnel of laboratories producing radiopharmaceuticals for use in PET.

\section{CONCLUSION}

Nuclear medicine comprises a variety of radionuclides used, medical procedures, but also a wide spectrum of professional groups involved in working with ionizing radiation. All this means that in the case of nuclear medicine, the need for routine dosimetry of eye lenses of employees of nuclear medicine facilities and radiopharmaceutical production units for positron emission tomography is difficult to determine. Detailed studies carried out, taking into account both the procedures performed by employees and the professional structure of individual facilities, make it possible to indicate the procedures and professional groups that will require more attention from radiological protection inspectors in the near future and where routine monitoring of personal eye dose equivalent $\mathrm{Hp}(3)$ is recommended as a prooptimization procedure. This situation occurs when working with the $99 \mathrm{~m} \mathrm{Tc}$ radionuclide and applies to chemical compounds labelled with this radionuclide and chemists from the quality control departments at
${ }^{18} \mathrm{~F}$-FDG production units. The recommendation for routine monitoring of personal eye dose equivalent $\mathrm{Hp}(3)$ also includes radiochemists during the dispensing of the doses of ${ }^{68} \mathrm{Ga}$-DOTA-TATE for patients. In other cases, the recommendation for the procedures for control of personal eye dose equivalent $\mathrm{Hp}(3)$ will be the responsibility of the radiation protection inspector.

Acknowledgements: This research was partially funded by the Nofer Institute of Occupational Medicine grant number16.2 and by the Ministry of Science and Higher Education of Poland, project number B1411500000542.02.

The authors would like to warmly thank all the people from the nuclear medicine departments and centers producing radiopharmaceuticals for their help in collecting the data.

\section{REFERENCES}

1. ICRP statement on tissue reactions and early and late effects of radiation in normal tissues and organsthreshold doses for tissue reactions in a radiation protection context, vol. 41, ICRP Publication no. 118, ICRP, Ottawa, Canada, 2012.

DOI: $10.1016 /$ j.icrp.2012.02.001

PMid: 22925378

2. The 2007 Recommendations of the International Commission on Radiological Protection, vol. 37, ICRP Publication no. 103, ICRP, Ottawa, Canada, 2007. Retrieved from: https://journals.sagepub.com/doi/pdf/10.1177/ANIB $37 \quad 2-4$ Retrieved on: Apr. 20. 2019

3. Implications for Occupational Radiation Protection of the New Dose Limit for the Lens of the Eye, TECDOC No. 1731, IAEA, Vienna, Austria, 2013.

Retrieved from:

https://wwwpub.iaea.org/MTCD/Publications/PDF/TE1731 web.pdf Retrieved on: May 12, 2019

4. J. Dabin et al., "Eye lens doses in nuclear medicine: A multicentric study in Belgium and Poland," Radiat. Prot. Dosim., vol. 170, no. 1 - 4, pp. 297 - 301, Sep. 2016. DOI: $10.1093 / \mathrm{rpd} / \mathrm{ncv} 538$ PMid: 26822424

5. S. Leide-Svegborn, "External radiation exposure of personnel in nuclear medicine from ${ }^{18} \mathrm{~F},{ }^{99 m} \mathrm{Tc}$ and ${ }^{131} \mathrm{I}$ with special reference to fingers, eyes and thyroid," Radiat. Prot. Dosim., vol. 149, no. 2, pp. $196-206$, Apr. 2012.

DOI: $10.1093 / \mathrm{rpd} / \mathrm{ncr} 213$

PMid: 21571739

6. Materiały $i$ sprzęt ochronny przed promieniowaniem $X$ i gamma -- Obliczanie oston statych, PN-86/J80001, Czerwiec 10, 1986.

(Materials and equipment protection against X-rays and gamma rays. Calculation the thickness of shields used against ionizing radiation, $\mathrm{PN}-86 / \mathrm{J}-80001$, Jun. 10, 1986.)

Retrieved from: http://www.narzedziownie.pl/?t=k\&i=202\&n=21274 Retrieved on: Jan. 18, 2019

7. K. A. Pachocki, A. Sackiewicz-Słaby, "Determining the current status and potential of nuclear medicine in 
Poland," Rocz. Państw. Zakt. Hig., vol. 64, no. 3, pp. 243 - 250, 2013.

Retrieved from:

http://wydawnictwa.pzh.gov.pl/roczniki_pzh/downloa d-article?id $=992$

Retrieved on: Aug. 22, 2019

8. Stan zdrowia ludnoœci polski w 2004 r., Główny urząd statystyczny, Warszawa, Polska, 2006.

(The health status of the Polish population in 2004, Central Statistical Office, Warsaw, Poland, 2006.)

Retrieved from:

https://stat.gov.pl/cps/rde/xbcr/gus/stan zdrowia 20 04.pdf

Retrieved on: Aug. 28, 2019

9. $X$ and gamma reference radiations for calibrating dosemeters and doserate meters and for determining their response as a function of photon energy, part 1 , ISO Report 4037-1, ISO, Geneva, Switzerland, 1997.

10. $X$ and gamma reference radiation for calibrating dosemeters and doserate meters and determining their response as a function of photon energy, part 3, ISO Report 4037-3, ISO, Geneva, Switzerland, 1999. Retrieved from:

https://www.sis.se/api/document/preview/615127/ Retrieved on: May 15, 2019

11. F. Vanhavere et al., "Measurements of eye lens doses in interventional radiology and cardiology: Final results of the ORAMED project," Radiat. Meas., vol. 46, no. 11, pp. 1243 - 1247, Nov. 2011. DOI: 10.1016/j.radmeas.2011.08.013

12. F. Vanhavere et al., ORAMED: Optimization of radiation protection of medical staff, Rep. 2012-02, EURADOS, Braunschweig, Germany, 2012.

Retrieved from: https://eurados.sckcen.be/-

Lmedia/Files/Eurados/documents/EURADOS Report 201202.pdf?la $=$ en\&hash $=$ 06DAE419D9DE476193197 19264086015D1D9143E

Retrieved on: Sep. 4, 2019

13. M. Wrzesień, "18F-FDG production procedures as a source of eye lens exposure to radiation," J. Radiol. Prot., vol. 38, no. 1, pp. 382 - 393, Feb. 2018.

DOI: $10.1088 / 1361-6498 /$ aaa287

PMid: 29447122

14. M. Wrzesień, L. Królicki, Ł. Albiniak, J. Olszewski, "Is eye lens dosimetry needed in nuclear medicine?," J. Radiol. Prot., vol. 38, no. 2, pp. 763 - 774, Jun. 2018. DOI: 10.1088/1361-6498/aabef5 PMid: 29667600

15. M. Wrzesień, Ł. Albiniak, "68Ga-DOTA-TATE-a source of eye lens exposure for nuclear medicine department workers," J. Radiol. Prot., vol. 38, no. 4, pp. 1512 1523, Dec. 2018.

DOI: $10.1088 / 1361-6498 /$ aaea8e

PMid: 30468680

16. The Council of European Union. (Dec. 5, 2013). Council Directive 2013/59/EURATOM. Laying down basic safety standards for protection against the dangers arising from exposure to ionising radiation, and repealing Directives 89/618/Euratom, 90/641/Euratom, 96/29/Euratom, 97/43/Euratom and 2003/122/Euratom.

Retrieved from:

https://eur-

lex.europa.eu/LexUriServ/LexUriServ.do?uri=OJ:L:20

14:013:0001:0073:EN:PDF

Retrieved on: Jul. 21, 2019 